\title{
Study of Morpho-Geometric Variables to Improve the Diagnosis in Keratoconus with Mild Visual Limitation
}

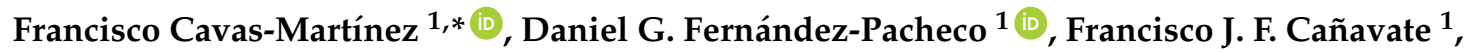 \\ Jose S. Velázquez-Blázquez ${ }^{1}$, Jose M. Bolarín ${ }^{2}$ and Jorge L. Alió ${ }^{3,4}$ \\ 1 Department of Graphical Expression, Technical University of Cartagena, 30202 Cartagena, Spain; \\ daniel.garcia@upct.es (D.G.F.-P.); francisco.canavate@upct.es (F.J.F.C.); jose.velazquez@upct.es (J.S.V.-B.) \\ 2 Department of Physical Chemistry, University of Murcia, 30071 Murcia, Spain; jmbolarin@gmail.com \\ 3 Department of Ophthalmology, Miguel Hernández University of Elche, 03202 Alicante, Spain; \\ jlalio@vissum.com \\ 4 Keratoconus Unit of Vissum Corporation Alicante, 03016 Alicante, Spain \\ * Correspondence: francisco.cavas@upct.es; Tel.: +34-968-338856
}

Received: 3 July 2018; Accepted: 20 July 2018; Published: 1 August 2018

\begin{abstract}
The validation of new methods for the diagnosis of incipient cases of Keratoconus (KC) with mild visual limitation is of great interest in the field of ophthalmology. During the asymmetric progression of the disease, the current diagnostic indexes do not record the geometric decompensation of the corneal curvature nor the variation of the spatial profile that occurs in singular points of the cornea. The purpose of this work is to determine the structural characterization of the asymmetry of the disease by using morpho-geometric parameters in KC eyes with mild visual limitation including using an analysis of a patient-specific virtual model with the aid of computer-aided design (CAD) tools. This comparative study included 80 eyes of patients classified as mild KC according to the degree of visual limitation and a control group of 122 eyes of normal patients. The metric with the highest area under the receiver operating characteristic (ROC) curve was the posterior apex deviation. The most prominent correlation was found between the anterior and posterior deviations of the thinnest point for the mild keratoconic cases. This new custom computational approach provides the clinician with a three-dimensional view of the corneal architecture when the visual loss starts to impair.
\end{abstract}

Keywords: geometric model; asymmetric evolution; computer-aided design; corneal topographer

\section{Introduction}

The human eye has four refractive surfaces, five refractive indexes, and four thicknesses [1]. The variation of any of these parameters affects the refractive state of the eye. Among all of them, the cornea is the most important parameter from a refractive point of view.

A perfect optical system would be completely symmetrical and would be free of distortion and transverse chromatic aberration. However, the cornea is not a perfect biological structure because its surfaces do not present symmetry of revolution in a healthy scenario, which entails the existence of deformations, misalignments, and decentralizations between its anterior and posterior surfaces and between its singular points (apex, vertex, and minimum thickness point) [2]. However, in a pathological scenario, the progression of the asymmetry in the corneal architecture contributes to a decrease in its optical capacity, which causes a loss of the patients' visual quality [3]. This decrease in optical functionality may have its origin in a physio-pathological mechanism derived from a pathology called keratoconus. Keratoconus $(\mathrm{KC})$ has an estimated prevalence of approximately 50-230 individuals 
per 100,000 people in the general population [4]. This asymmetrical ectatic disorder is geometrically characterized by [5] the details below.

- a geometric decompensation or progressive distortion of the corneal curvature from a singular point denominated the corneal apex.

- a decompensation of the spatial profile of pachymetry, which is described as an annular increase/decrease of its thickness from a singular point called the minimum thickness point.

Both characterizations involve a local geometric alteration in the cornea during keratoconus. Depending on the level of corneal deformation, it leads to a gradual deterioration of visual performance [6-8].

Several reports had the task to assess the different stages of KC and their corneal deformations by using different devices and analyses $[9,10]$. Most of the studies performed have only taken into consideration the morphological features to discriminate the different stages of the disease without considering other important clinical aspects directly correlated to the corneal visual disability [11].

As recently reported, the corneal geometric modeling has been proposed for the study of ectasia characterization [12]. Nevertheless, to the author's knowledge, this new tool has not been considered for the study of KC eyes with mild impaired visual function as graded along the evolution of the disease. Patient-specific 3D modeling may help to better recognize the changes that happen in the cornea when $\mathrm{KC}$ is developed and it correlates with vision decay as the disease evolves [11] (Figure 1). There is an important threshold between normality and, when the disease starts to clinically affect the patient, a better understanding of these cases could help the management of ectasia in the clinical practice.

The purpose of the current study was to determine the geometrical profile and novel correlations of the corneal deformation for $\mathrm{KC}$ eyes with mild visual limitation compared to normal corneas by using the morphogeometric custom modeling analysis. Our aim was to understand the modeled changes observed in the keratoconic cornea with a mild visual loss and also attempt to find a morpho-geometrical correlation.

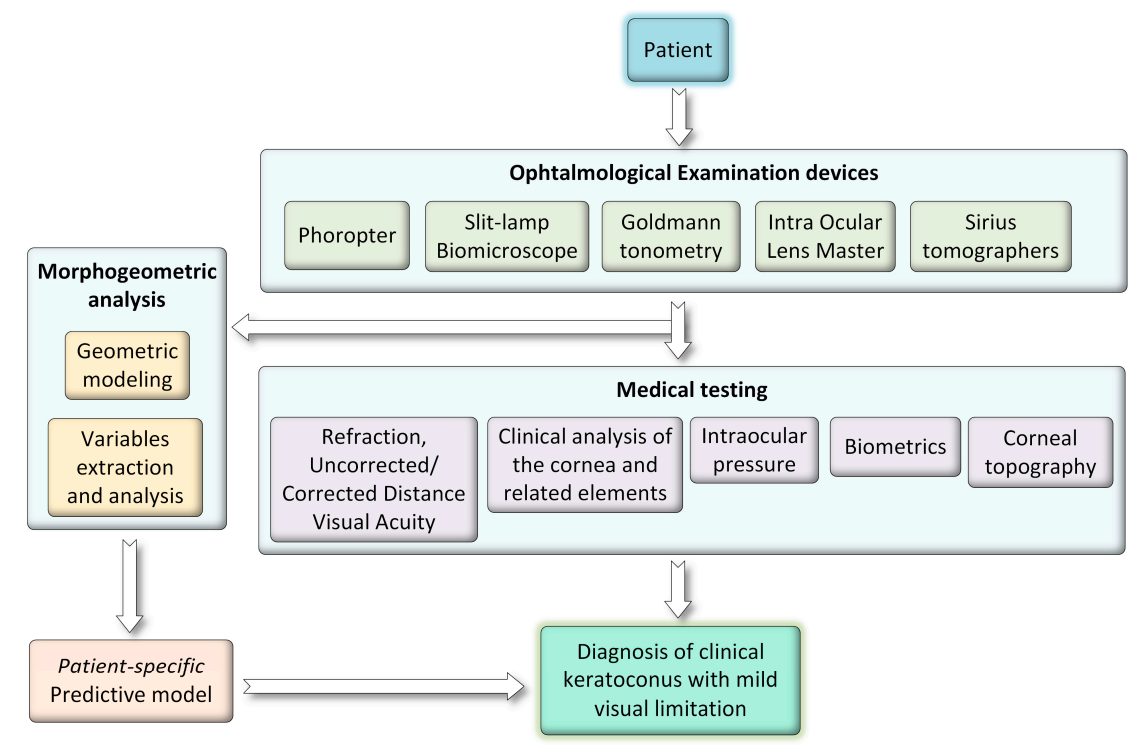

Figure 1. Use of a predictive patient-specific model for the diagnosis of keratoconus with mild visual limitation.

\section{Patients and Methods}

\subsection{Patients}

The study included a total of 202 eyes of 202 patients (122 normal and 80 keratoconic cases) enrolled at Vissum Instituto Oftalmologico Alicante, Spain (Vissum) who were adequately informed 
about the clinical study and voluntarily signed their consent to participate. The study was ratified by the clinic's Institutional Review Board in compliance with the ethical restrictions established in the Declaration of Helsinki (Seventh revision, October 2013, Fortaleza, Brasil).

All patients were selected, according to the Cooperative Research Thematic Network (RETICS) grading $[8,11]$ based on the limitation of spectacle corrected distance visual acuity (CDVA) and also taking into account corneal aberrations, internal astigmatism, and corneal biomechanical properties. Inclusion criteria were patients diagnosed as KC eyes with mild visual impairment $(0.6<$ CDVA $\leq 0.9$ in decimal scale, or 20/33 < CDVA $\leq 20 / 22$ Snellen), normal visual acuity achieved by fitting a rigid gas permeable contact lens, corneal topography revealing a localized steepening, and/or an asymmetric bowtie pattern with or without skewed radial axis. The exclusion criteria were the following. Any previous ocular surgery, ocular surface inflammation, moderate to severe dry eye or other active ocular comorbidity, or use of contact lenses within the four weeks prior to the first visit.

The control group comprised 122 normal eyes of 122 patients. This group was selected at random by subjects assessed in the refractive surgery department. Exclusion criteria for this range were the following: participants with any ocular disease, topographic irregularities or abnormal aberrometry, familial history of $\mathrm{KC}$, contact lens wearing within four weeks, or those whose eyes had undergone any previous surgery.

\subsection{Ophthalmological Examination}

A detailed and uniform ophthalmologic examination was performed in all cases, according to the clinical standards [3]. Testing sessions consisted of a minimum of three corneal topographies for each cornea made with Sirius Tomographer (CSO, Florence, Italy), which was always carried out by the same experienced examiner. Only the best topographies with the highest acquisition quality for the Scheimpflug images were selected for providing data.

\subsection{Morpho-Geometric Reconstruction of the Cornea}

This analysis defined by the authors was conducted on all participants. The corneal morpho-geometric reconstruction procedure consists of the following successive stages (Figure 2): (i) obtaining the point clouds of both corneal surfaces, (ii) geometrically reconstructing the corneal surfaces, and (iii) generating a representative solid model of the cornea.

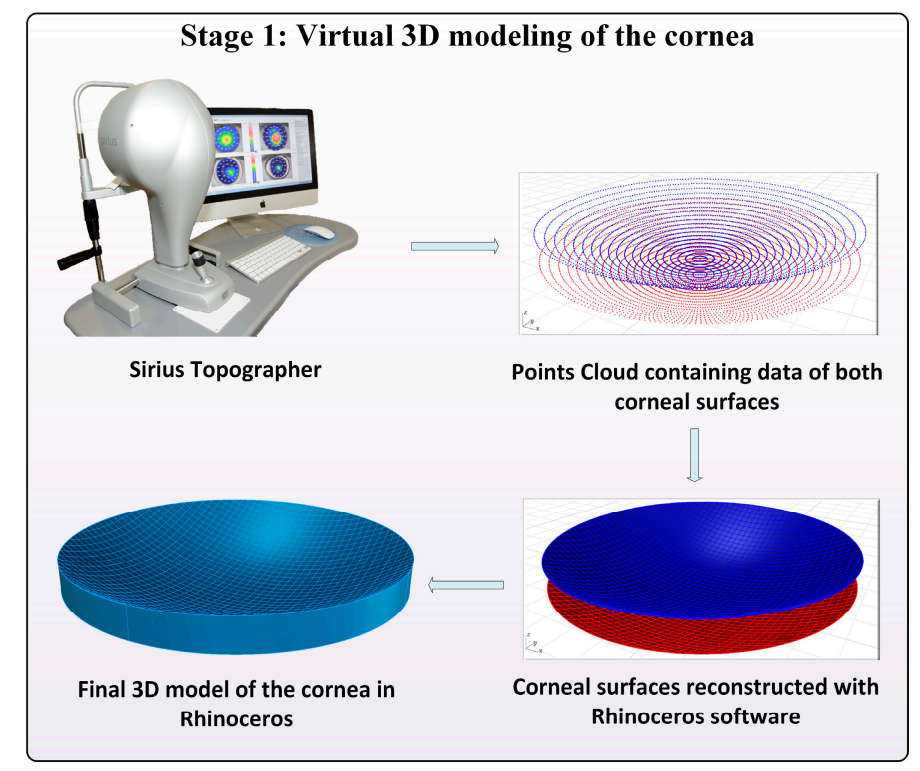

Figure 2. Scheme of the morpho-geometric reconstruction of the cornea. 


\subsubsection{Acquisition of the Point Clouds}

The point clouds that represent the geometry of the corneal surfaces were generated from the data provided by a Sirius corneal topographer (CSO, Florence, Italy). This topographer offers an Excel file that includes information regarding both corneal surfaces for each patient. Within this information, the most reliable information to perform geometric modeling is the raw altimetry data of the anterior and posterior elevations (radii of Placido's disc rings), which have not been manipulated by any software process inside the topographer [13].

\subsubsection{Geometric Reconstruction of Corneal Surfaces}

The point clouds representative of corneal geometry are later imported by the surface reconstruction software Rhinoceros v5.0 (MCNeel \& Associates, Seattle, WA, USA). This software uses a mathematical model to generate surfaces based on non-uniform rational B-splines (NURBS) [14] and its validity in the Biomedical Engineering [15-18] and Ophthalmology [19-22] fields has been widely demonstrated. For this study, the "patch" surface generation function was used to reconstruct both corneal surfaces. These surfaces were then connected by their vertex in relation to the optical axis and the perimetral surface was obtained.

\subsubsection{Generation of the Solid Model of the Cornea}

The reconstructed surfaces of each case by Rhinoceros were later imported into the solid modeling software SolidWorks (Dassault Systèmes, Vélizy-Villacoublay, France), which permitted to generate a solid model representative of the real and customized geometry of the cornea.

\subsection{Characterization of the Cornea}

After obtaining the 3D patient-specific model of the cornea in SolidWorks, it can be used to calculate certain morpho-geometric variables, which will characterize the analyzed cornea (Figure 3). Table 1 shows a detailed description of the geometrical variables analyzed for the KC group during the present study.

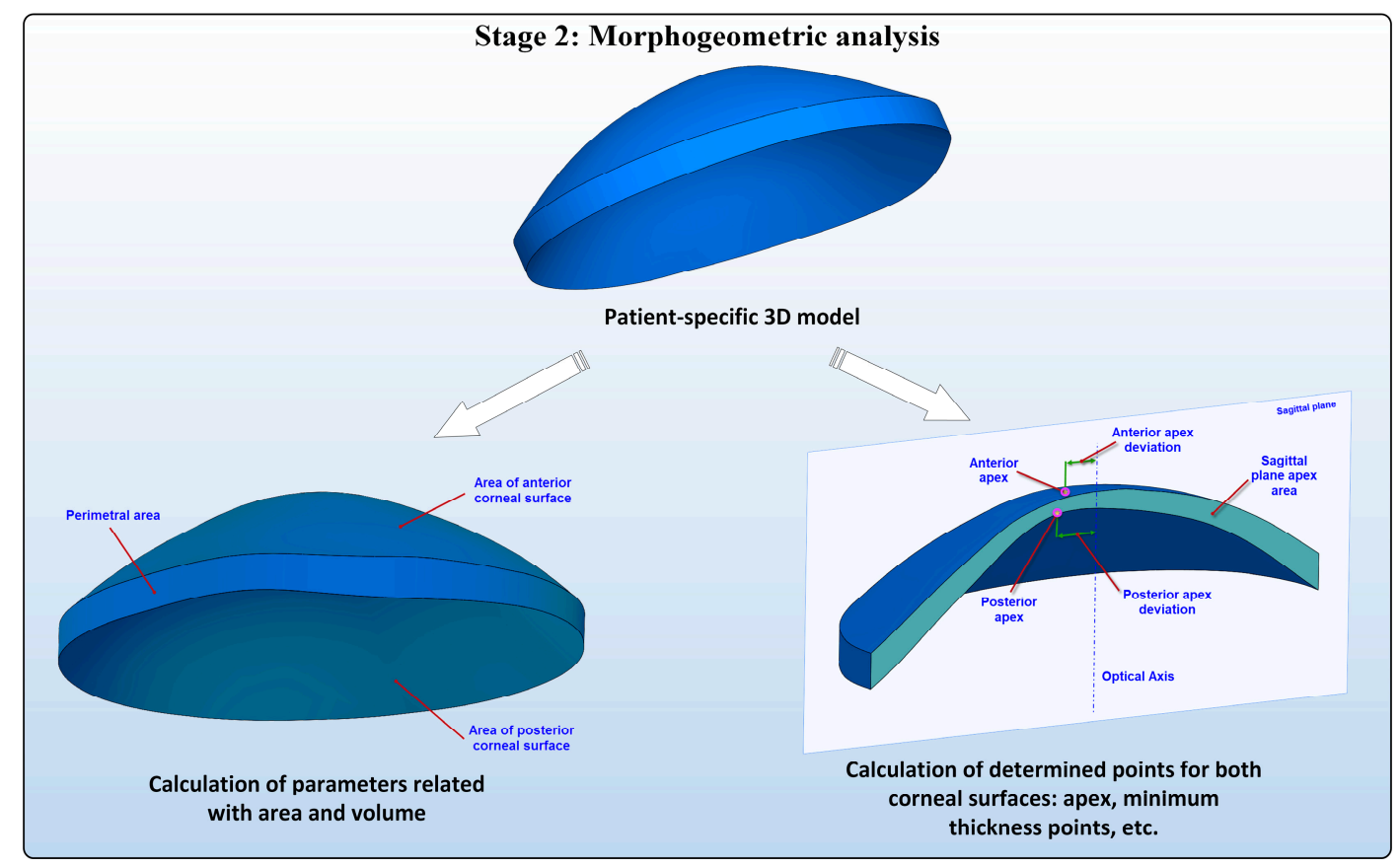

Figure 3. Scheme of the Characterization of the Cornea. 
Table 1. Corneal morpho-geometric variables analyzed in the study.

\begin{tabular}{|c|c|c|}
\hline $\begin{array}{l}\text { Morpho-Geometric } \\
\text { Variable }\end{array}$ & Acronym & Description \\
\hline Corneal volume $\left(\mathrm{mm}^{3}\right)$ & $\mathrm{CV}$ & Volume defined by the solid model generated \\
\hline $\begin{array}{l}\text { Anterior/Posterior corneal } \\
\text { surface area }\left(\mathrm{mm}^{2}\right)\end{array}$ & $\mathrm{A}_{\text {ant }} / \mathrm{A}_{\text {post }}$ & Area of the exterior/interior surface \\
\hline Corneal surface area $\left(\mathrm{mm}^{2}\right)$ & $A_{\text {tot }}$ & Total area defined by the solid model generated \\
\hline $\begin{array}{l}\text { Posterior sagittal plane } \\
\text { apex area }\left(\mathrm{mm}^{2}\right)\end{array}$ & A postapex & $\begin{array}{l}\text { Area of the cornea within the sagittal plane passing } \\
\text { through the optical axis and the apex of the posterior } \\
\text { corneal surface }\end{array}$ \\
\hline $\begin{array}{l}\text { Anterior/Posterior apex } \\
\text { deviation }(\mathrm{mm})\end{array}$ & $D_{\text {antapex }} / D_{\text {postapex }}$ & $\begin{array}{l}\text { Distance from the optical axis to the apex of the } \\
\text { anterior/posterior corneal surfaces }\end{array}$ \\
\hline $\begin{array}{l}\text { Sagittal plane area at } \\
\text { minimum thickness } \\
\text { point }\left(\mathrm{mm}^{2}\right)\end{array}$ & A postmct & $\begin{array}{l}\text { Area of the cornea within the sagittal plane passing } \\
\text { through the optical axis and the minimum thickness } \\
\text { point of the posterior corneal surface }\end{array}$ \\
\hline $\begin{array}{l}\text { Anterior/Posterior } \\
\text { minimum thickness point } \\
\text { deviation }(\mathrm{mm})\end{array}$ & $\mathrm{D}_{\text {antmct }} / \mathrm{D}_{\text {postmct }}$ & $\begin{array}{l}\text { Distance in the } X Y \text { plane from the optical axis to the } \\
\text { minimum thickness points of the anterior/posterior } \\
\text { corneal surfaces }\end{array}$ \\
\hline Center of mass $X, Y, Z(\mathrm{~mm})$ & $\mathrm{CM}_{\mathrm{x}} / \mathrm{CM}_{\mathrm{y}} / \mathrm{CM}_{\mathrm{z}}$ & Center of mass coordinates $X, Y, Z$ of the solid \\
\hline
\end{tabular}

The main outcome measure of this study was to define the model that the keratoconic cornea follows when mild visual loss is associated with corneal deformation. The second outcome was the correlation coefficients, sensitivity, and specificity of this new KC detection method.

\subsection{Statistical Analysis}

All data were analyzed using IBM SPSS 19.0 software (IBM Corp., Armonk, NY, USA). The statistical analysis included descriptive statistics for both normal and $\mathrm{KC}$ groups to demonstrate the distribution of the thirteen morpho-geometric variables in more detail. Normality was checked using the Kolmogorov-Smirnov test. When parametric analysis was possible, the Student t-test for unpaired data was used as a comparison between groups. When the normality condition was met, groups were compared using a Student $t$-test for unpaired data. For all other situations, a Mann-Whitney test was used. A p-value lower than 0.05 was considered significant in all statistical tests. Correlation between parameters was assessed using Pearson coefficients (for normally distributed data) or Spearman coefficients (not normally distributed). With the aim of quantifying the strength of the correlation between the two groups, a linear regression was executed.

For all metrics, we applied receiver operating characteristic (ROC) curves to determine the overall predictive accuracy by plotting sensitivity versus 1 -specifity.

\section{Results}

From a total of 202 eyes of 202 patients, the KC group comprised 80 eyes of 80 patients [ 29 women $(36.2 \%)$ and 51 men $(63.8 \%)$ with a mean age of 41.8 years \pm 13.1 ranging from 16 to 72 years]. The control group was composed of 122 normal eyes of 122 patients (54 women (44.2\%) and 68 men $(55.8 \%))$ with a mean age of $34.89 \pm 7.8$ years ranging from 19 to 64 years. There was no statistical difference regarding the age between groups $(p>0.05)$.

Regarding the KC group, the mean value of the posterior apex deviation $(0.19 \pm 0.10 \mathrm{~mm})$ was higher than the anterior apex deviation $(0.01 \pm 0.02 \mathrm{~mm})$ while the mean deviation at the minimum thickness point of the anterior and posterior curvatures was $1.11 \pm 0.48 \mathrm{~mm}$ and $1.04 \pm 0.45 \mathrm{~mm}$, respectively. From the metrics of the center of mass coordinates $X, Y$, and $Z$, the value in $Z$ reached the largest one with $0.78 \pm 0.04 \mathrm{~mm}$. The total corneal volume resulted in an average of $23.60 \pm 2.28 \mathrm{~mm}^{3}$. 
For metrics from the total corneal surface, the anterior surface, and the posterior surface, the average achieved areas were $103.61 \pm 1.62 \mathrm{~mm}^{2}, 43.39 \pm 0.35 \mathrm{~mm}^{2}$, and $44.70 \pm 0.56 \mathrm{~mm}^{2}$, respectively. For the measurement of the sagittal plane area, the mean values reached were $3.91 \pm 0.37 \mathrm{~mm}^{2}$ (posterior surface) and $3.89 \pm 0.39 \mathrm{~mm}^{2}$ (at the minimum thickness point of the posterior surface). The descriptive values of the thirteen corneal morpho-geometric variables and their distribution in more detail are summarized in Table 2 for both keratoconic and control groups.

Table 2. Summary of the modeled morpho-geometric variables in control and keratoconus with mild visual limitation groups. SD (standard deviation).

\begin{tabular}{|c|c|c|c|}
\hline \multirow{2}{*}{ Measurement } & Normal Group $n=122$ & $\begin{array}{l}\text { Keratoconus Group } \\
\text { with Mild Visual Limitation } n=80\end{array}$ & \multirow[b]{2}{*}{$p$ Value } \\
\hline & $\begin{array}{c}\text { Mean (SD) } \\
\text { Median (Range) }\end{array}$ & $\begin{array}{c}\text { Mean (SD) } \\
\text { Median (Range) }\end{array}$ & \\
\hline $\mathrm{CV}\left(\mathrm{mm}^{3}\right)$ & $\begin{array}{c}25.70(1.49) \\
25.70(22.99 \text { to } 29.50)\end{array}$ & $\begin{array}{c}23.60(2.28) \\
23.31(16.95 \text { to } 27.74)\end{array}$ & $<0.001$ \\
\hline $\mathrm{A}_{\text {ant }}\left(\mathrm{mm}^{2}\right)$ & $\begin{array}{c}43.08(0.14) \\
43.08(43.06 \text { to } 43.11)\end{array}$ & $\begin{array}{c}43.39(0.35) \\
43.26(42.85 \text { to } 44.36)\end{array}$ & $<0.001$ \\
\hline $\mathrm{A}_{\text {post }}\left(\mathrm{mm}^{2}\right)$ & $\begin{array}{c}44.24(0.27) \\
44.25(44.19 \text { to } 44.28)\end{array}$ & $\begin{array}{c}44.70(0.56) \\
44.57(43.64 \text { to } 46.36)\end{array}$ & $<0.001$ \\
\hline $\mathrm{A}_{\text {tot }}\left(\mathrm{mm}^{2}\right)$ & $\begin{array}{c}103.87(1.14) \\
103.78(100.73 \text { to } 106.01)\end{array}$ & $\begin{array}{c}103.61(1.62) \\
103.70(99.97 \text { to } 106.51)\end{array}$ & 0.205 \\
\hline $\mathrm{A}_{\text {postapex }}\left(\mathrm{mm}^{2}\right)$ & $\begin{array}{c}4.31(0.25) \\
4.30(4.27 \text { to } 4.36)\end{array}$ & $\begin{array}{c}3.91(0.37) \\
3.82(3.00 \text { to } 4.66)\end{array}$ & $<0.001$ \\
\hline$A_{\text {postmct }}\left(\mathrm{mm}^{2}\right)$ & $\begin{array}{c}4.30(0.25) \\
4.29(4.26 \text { to } 4.35)\end{array}$ & $\begin{array}{c}3.89(0.39) \\
3.81(3.80 \text { to } 3.98)\end{array}$ & $<0.001$ \\
\hline $\mathrm{D}_{\text {antapex }}(\mathrm{mm})$ & $\begin{array}{c}0.00(0.00) \\
0.00(0.00 \text { to } 0.00)\end{array}$ & $\begin{array}{c}0.01(0.02) \\
0.00(0.00 \text { to } 0.07)\end{array}$ & $<0.001$ \\
\hline $\mathrm{D}_{\text {postapex }}(\mathrm{mm})$ & $\begin{array}{c}0.06(0.02) \\
0.06(0.06 \text { to } 0.07)\end{array}$ & $\begin{array}{c}0.19(0.10) \\
0.18(0.02 \text { to } 0.45)\end{array}$ & $<0.001$ \\
\hline $\mathrm{CM}_{\mathrm{x}}(\mathrm{mm})$ & $\begin{array}{c}0.02(0.04) \\
0.03(0.02 \text { to } 0.04)\end{array}$ & $\begin{array}{c}0.01(0.05) \\
0.02(-0.09 \text { to } 0.12)\end{array}$ & 0.073 \\
\hline $\mathrm{CM}_{\mathrm{y}}(\mathrm{mm})$ & $\begin{array}{c}0.03(0.01) \\
0.03(0.00 \text { to } 0.08)\end{array}$ & $\begin{array}{c}0.02(0.04) \\
0.02(-0.09 \text { to } 0.28)\end{array}$ & $<0.001$ \\
\hline $\mathrm{CM}_{\mathrm{z}}(\mathrm{mm})$ & $\begin{array}{c}0.77(0.02) \\
0.77(0.76 \text { to } 0.78)\end{array}$ & $\begin{array}{c}0.78(0.04) \\
0.78(0.71 \text { to } 0.90)\end{array}$ & 0.006 \\
\hline $\mathrm{D}_{\text {antmct }}(\mathrm{mm})$ & $\begin{array}{c}0.84(0.23) \\
0.83(0.80 \text { to } 0.88)\end{array}$ & $\begin{array}{c}1.11(0.48) \\
1.05(0.33 \text { to } 3.11)\end{array}$ & $<0.001$ \\
\hline $\mathrm{D}_{\text {postmct }}(\mathrm{mm})$ & $\begin{array}{c}0.77(0.21) \\
0.76(0.73 \text { to } 0.81)\end{array}$ & $\begin{array}{c}1.04(0.45) \\
0.99(0.28 \text { to } 2.94)\end{array}$ & $<0.001$ \\
\hline
\end{tabular}

In comparison to the control group, the differences between groups were statistically significant for overall corneal metrics, which includes total volume $(p<0.001)$, anterior surface area $(p<0.001)$, anterior apex deviation $(p<0.001)$, anterior minimum thickness point deviation $(p<0.001)$, posterior surface area $(p<0.001)$, posterior sagittal plane apex area $(p<0.001)$, sagittal plane area at minimum thickness point $(p<0.001)$, posterior apex deviation $(p<0.001)$, posterior minimum thickness point deviation $(p<0.001)$, center of mass $Y(p<0.001)$, and center of mass $Z(p=0.006)$. In this regard, the modeled variables with no statistical difference for groups discrimination were the center of mass $X(p=0.073)$ and the total corneal surface area $(p=0.205)$.

When applying the ROC analysis, the highest area under the curve (AUC) was reached by the corneal posterior apex deviation. Considering an AUC greater than 0.7, the variables found were a 
posterior apex deviation (area: 0.904 , sensitivity: $88.8 \%$, specificity: $81.1 \%$, cutoff: $\geq 0.0846 \mathrm{~mm}$, $p=0.000$ ), an anterior apex deviation (area: 0.866 , sensitivity: $76.3 \%$, specificity: $95.9 \%$, cutoff: $\geq 0.001 \mathrm{~mm}, p=0.000$ ), and a posterior corneal surface area (area: 0.761 , sensitivity: $76.3 \%$, specificity: $64.8 \%$, cutoff: $\geq 43.16 \mathrm{~mm}^{2}, p=0.000$ ). The curves derived from these significant AUC values are demonstrated in Figure 4.
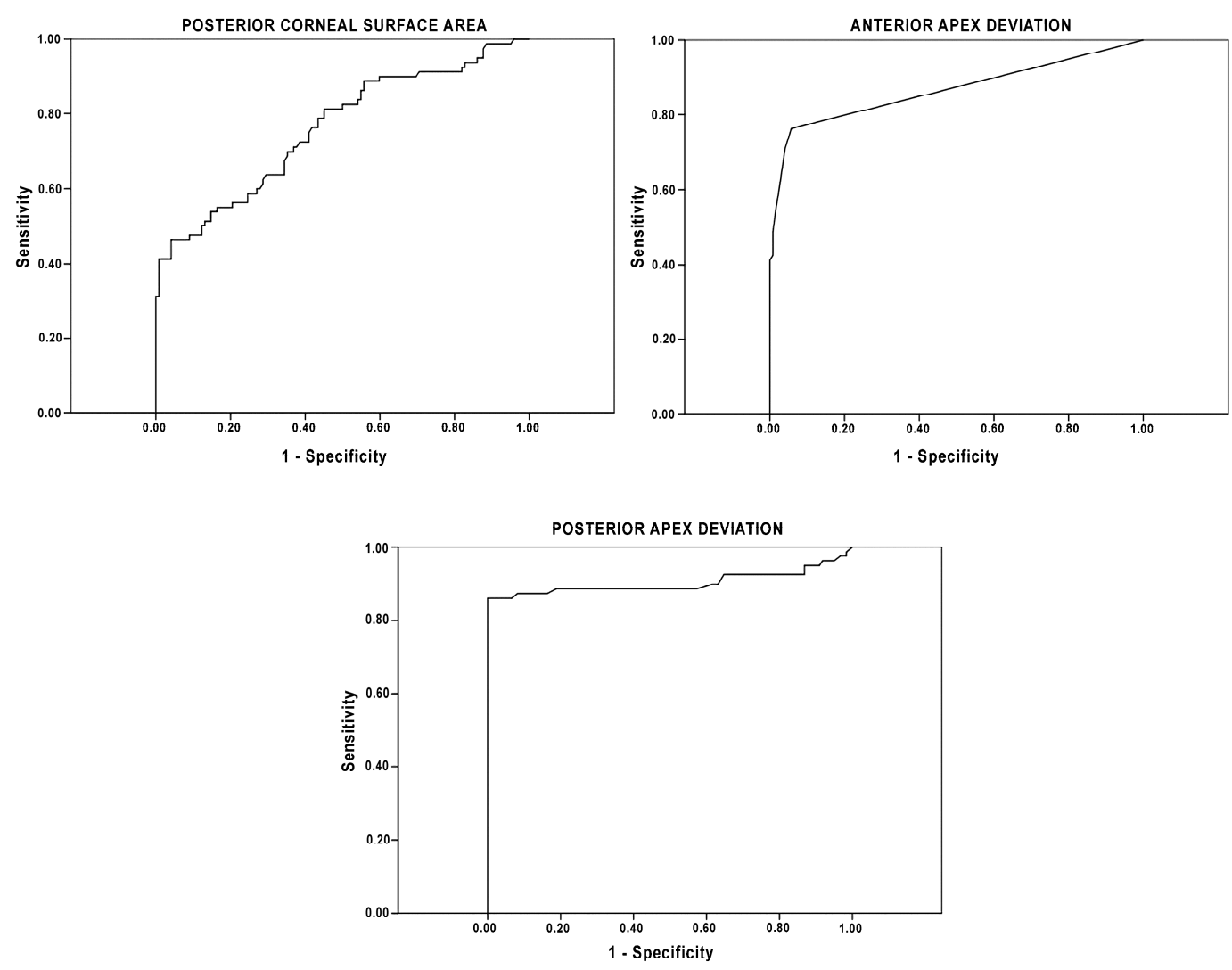

Figure 4. Combined receiver operating characteristic (ROC) curves for the modeled parameters with the highest predictive accuracy diagnosing keratoconus with mild visual limitation (plotted only variables with the area under the curve over 0.7 ).

Table 3 summarizes the statistically significant correlations between all the modeled morpho-geometric variables for the KC group. Table 4 also shows the significant correlations for the normal group.

Table 3. The significant correlation coefficient values for the modeled variables in the keratoconus group.

\begin{tabular}{ccc}
\hline \multicolumn{2}{c}{ Keratoconus Group with Mild Visual Limitation $(\boldsymbol{n}=\mathbf{8 0})$} \\
\hline Measurement Correlation & Correlation Coefficient & $\boldsymbol{p}$ Value \\
\hline $\mathrm{A}_{\text {postapex }} / \mathrm{CV}$ & 0.969 & 0.000 \\
$\mathrm{~A}_{\text {ant }} / \mathrm{A}_{\text {post }}$ & 0.853 & 0.000 \\
$\mathrm{CV} / \mathrm{A}_{\text {tot }}$ & 0.699 & 0.000 \\
$\mathrm{~A}_{\text {ant }} / \mathrm{CM}_{\mathrm{z}}$ & 0.627 & 0.000 \\
$\mathrm{~A}_{\text {post }} / \mathrm{CM}_{\mathrm{z}}$ & 0.766 & 0.000 \\
$\mathrm{~A}_{\text {tot }} / \mathrm{CM}_{\mathrm{z}}$ & 0.816 & 0.000 \\
$\mathrm{~A}_{\text {postapex }} / \mathrm{A}_{\text {postmct }}$ & 0.989 & 0.000 \\
$\mathrm{CV} / \mathrm{A}_{\text {postmct }}$ & 0.978 & 0.000 \\
$\mathrm{D}_{\text {antmct }} / \mathrm{D}_{\text {postmct }}$ & 0.996 & 0.000 \\
\hline
\end{tabular}


Table 4. The significant correlation coefficient values for the modeled variables in the normal group.

\begin{tabular}{|c|c|c|}
\hline \multicolumn{3}{|c|}{ Normal Group ( $n=122)$} \\
\hline Measurement Correlation & Correlation Coefficient & $p$ Value \\
\hline $\mathrm{A}_{\text {postapex }} / \mathrm{CV}\left(\mathrm{mm}^{3}\right)$ & 0.987 & 0.000 \\
\hline$A_{\text {postapex }} / A_{\text {tot }}$ & 0.814 & 0.000 \\
\hline $\mathrm{A}_{\text {tot }} / \mathrm{CM}_{\mathrm{z}}$ & 0.723 & 0.000 \\
\hline $\mathrm{A}_{\text {ant }} / \mathrm{A}_{\text {post }}$ & 0.774 & 0.000 \\
\hline $\mathrm{A}_{\text {post }} / \mathrm{A}_{\text {tot }}$ & 0.649 & 0.000 \\
\hline $\mathrm{A}_{\text {post }} / \mathrm{CM}_{\mathrm{z}}$ & 0.719 & 0.000 \\
\hline $\mathrm{CV} / \mathrm{A}_{\text {tot }}$ & 0.858 & 0.000 \\
\hline $\mathrm{CV} / \mathrm{CM}_{\mathrm{z}}$ & 0.768 & 0.000 \\
\hline $\mathrm{A}_{\mathrm{tot}} / \mathrm{CM}_{\mathrm{z}}$ & 0.943 & 0.000 \\
\hline $\mathrm{A}_{\text {postapex }} / \mathrm{CM}_{\mathrm{z}}$ & 0.723 & 0.000 \\
\hline $\mathrm{A}_{\text {postmct }} / \mathrm{A}_{\text {postapex }}$ & 0.996 & 0.000 \\
\hline $\mathrm{CV} / \mathrm{A}_{\text {postmct }}$ & 0.987 & 0.000 \\
\hline $\mathrm{A}_{\text {tot }} / \mathrm{A}_{\text {postmct }}$ & 0.813 & 0.000 \\
\hline $\mathrm{CM}_{\mathrm{z}} / \mathrm{A}_{\text {postmct }}$ & 0.730 & 0.000 \\
\hline $\mathrm{D}_{\text {antmct }} / \mathrm{D}_{\text {postmct }}$ & 0.988 & 0.000 \\
\hline
\end{tabular}

The regression analysis among the mild KC group (Figure 5) revealed significant and strong correlations between the morpho-geometric variables $(p=0.000)$, which is shown below.
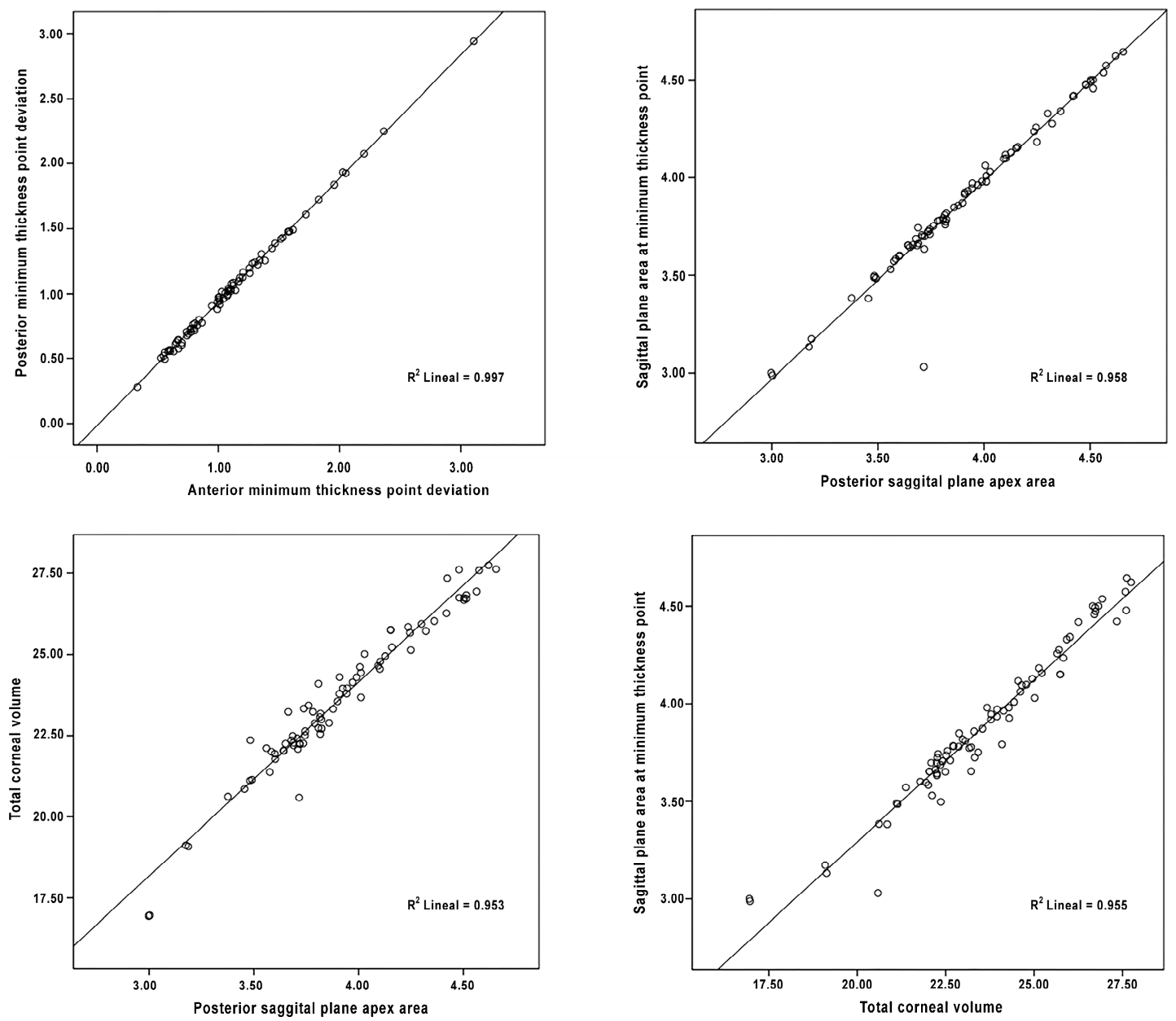

Figure 5. Scattergram plot showing the most significant relationships between the morpho-geometric variables for the keratoconus group $(n=80)$. 
Posterior minimum thickness point deviation $=0.944 \times$ Anterior minimum thickness

$$
\text { point deviation }+0.236\left(R^{2}=0.997\right)
$$

Sagittal plane area at minimum thickness point $=1.05 \times$ Posterior sagittal plane apex

$$
\text { area }+0.018\left(R^{2}=0.958\right)
$$

Total corneal volume $=5.757 \times$ Posterior sagittal plane apex area $+1.197\left(R^{2}=0.953\right)$

Sagittal plane area at minimum thickness point $=0.16 \times$ Total corneal volume +

$$
0.136\left(R^{2}=0.955\right)
$$

According to the regression analysis for the normal group (Figure 6), the most significant correlations between the corneal metrics extracted from the reconstructed model are shown below $(p=0.000)$.

Center of mass $\mathrm{Z}=0.0195 \times$ Total cornea surface area $-1.255\left(R^{2}=0.907\right)$

Posterior sagittal plane apex area $=1.005 \times$ Sagittal plane area at minimum thickness

$$
\text { point }-0.031\left(R^{2}=0.994\right)
$$

Total corneal volume $=5.829 \times$ Posterior sagittal plane apex area $+0.633\left(R^{2}=0.978\right)$

Sagittal plane area at a minimum thickness point $=0.166 \times$ Total corneal volume $+0.034\left(R^{2}=0.978\right)$.
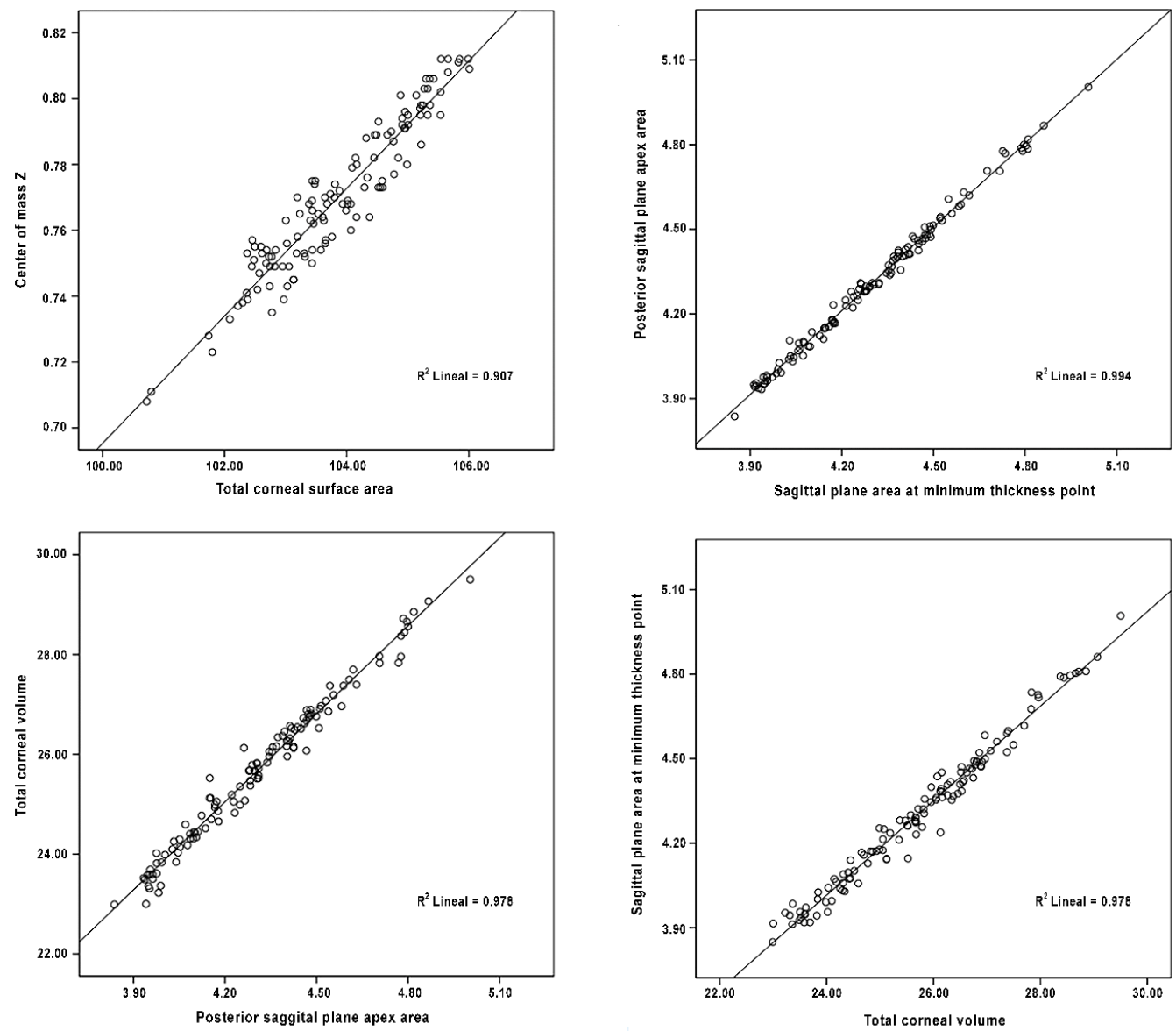

Figure 6. Scattergram plot showing the most significant relationships between the morpho-geometric variables for the normal group $(n=122)$. 


\section{Discussion}

The validation of new methods for the diagnosis of incipient cases of $\mathrm{KC}$ or with mild visual loss is of great interest in the field of ophthalmology since there are several clinical treatments that would permit the end of further development of the disease [23]. For this reason, this work tries to perform a morphological analysis of the corneal structure's response to both the linear decompensation and the annular profile defined in the singular points of corneal surfaces. This procedure will contribute to a better differentiation between the corneas in a healthy scenario and in an incipient stage of the development of the disease based on a new approach and interpretation of the corneal architecture in KC corneas with visual limitations.

The first study [24] in KC corneas with mild visual limitation analyzed the corneal thinning and found that such thinning was moved with respect to the corneal vertex as an asymmetric response to the development of the pathology. Subsequently, another study analyzed the geometric response in normal eyes and the initial phases of KC. However, their conclusions were insufficient because they did not obtain consistent values of thinning measures in corneas with similar geometries [25]. A recent study showed that, when morphological analysis and corneal thickness of eyes are combined with $\mathrm{KC}$, both are involved in the pathogenesis of the disease [26]. However, the geometric profile and the relationships that allow modeling of the progression of $\mathrm{KC}$ with mild visual loss have not yet been analyzed from these geometric models.

Other authors $[25,27,28]$ consider a finite element model for KC aimed to simulate the behavior of the deformation on model corneas. However, they did not take into account the patient-specific corneal tomography. Alternatively, another study [29] that included progressive KC eyes was performed by gathering the elevation data from Zernike coefficients. Unlike our method, the $\mathrm{x}, \mathrm{y}$, and $\mathrm{z}$ coordinates from the elevation maps of Pentacam were linearly interpolated into the Zernike polynomials by a natural cubic spline. For this approach, the discretization of the model was derived from estimated data by using the blending function method. Therefore, the corneal surface reconstruction algorithm could not be properly inferred by this fitting procedure, which has been discussed in the literature [30-32]. In addition, the small sample size could be considered a drawback of these previously mentioned reports.

This analysis outlines the presence of mild visual impairment in the current series using a grading system primarily based on the criteria of visual evolution. In this regard, the present study set out the $3 \mathrm{D}$ characterization with patient-specific geometry of these $\mathrm{KC}$ cases in stages where a loss of visual function begins to occur. While the corneal refractive power is mostly determined by the anterior curvature [33], changes from the posterior surface are usually related to mild visual degradation [34]. The present report portrays the first study to assess the correlations of this geometrical method between the anterior and posterior corneal surfaces of keratoconic eyes with mild visual dysfunction.

In the present study, almost all mean differences were statistically significant $(p=0.00)$ between $\mathrm{KC}$ corneas with mild visual limitation and normal eyes. The proposed variables were obtained from the raw data of Sirius using a 3D point cloud, which generated a reliable solid model striving for consistent noise-suppressing properties. This Scheimpflug-Placido system used in a recent study [35] demonstrated more robust measurements in terms of repeatability (coefficients of variation $=0$ ) and also outstanding levels of reproducibility and inter-device agreement in comparison to other devices studied.

Regarding the ROC analysis, the apex deviation of the posterior surface showed the highest discriminant coefficient (AUC, 0.904), which occurs because the apex is the maximum curvature point of the corneal surface According to a previous publication [36], the posterior curvature might have an impact on visual performance. We postulate that measuring the posterior apex deviation value is the most proficient way of characterizing the geometric profile of the KC stage in which a decrease of the visual acuity begins to occur. Moreover, the anterior apex deviation also shows an acceptable discrimination capability (AUC, 0.866$)$. However, its sensitivity was lower $(76.3 \%)$ in this investigation. 
Other authors [37] recently reported that topographic indices and posterior elevation values from the Galilei device were significantly correlated with visual function.

This study also assessed the relationship of the geometrical pattern of the anterior and posterior corneal curvatures. Other authors, for a different purpose, found strong statistical correlations between the anterior and posterior shape factors for keratoconic corneas [38]. Regarding the minimum thickness point deviations from both corneal surfaces, we found significant differences between groups. Furthermore, for keratoconic eyes, the strongest correlation value yielded in this investigation was between the anterior and posterior deviations of the thinnest point $\left(R^{2}=0.997, p=0.000\right)$. Lopes et al. [39] demonstrated a robust correlation between apex deviation and the pachymetric progression index of the front and back elevations with CDVA of the analyzed patients.

Although there are other methods [40-42] describing corneal volume reduction among the disease evolution, in our study, this metric was investigated in $\mathrm{KC}$ eyes based on the beginning of visual impairment. With respect to the total volume, we found a significant difference in comparison to the control group. We also found a significant positive correlation between the corneal volume with the sagittal plane apex area of the posterior surface $\left(R^{2}=0.953, p=0.000\right)$ and with the sagittal plane area at a minimum thickness point $\left(R^{2}=0.955, p=0.000\right)$. Likewise, the correlations described were strongly achieved for normal eyes that were analyzed.

In conclusion, the morphological analysis of the corneal response with geometric models to both the linear decompensation and the annular profile in the mentioned singular points support the hypothesis of a focal weakening in incipient phases of the KC development. The most predictive accuracy using this geometrical reconstruction of KC eyes associated with mild visual loss resulted clearly from the posterior apex displacement. The anterior and posterior deviations of the thinnest point were considerably correlated among mild keratoconic corneas in the specific geometry of the 3D model, which was obtained with the new method described. The proposed morpho-geometric metrics showed significant differences between groups, which may lead to a further advancement of a more tailored disease management based on the evolution of corneal visual impairment. This may also presumably be extended to other Scheimpflug systems. This computational custom approach determines the characterization profile of keratoconic modeling in eyes with mild visual limitation. This procedure provides the clinician with a three-dimensional view of corneal architecture when mild visual loss happens and allows a reliable diagnosis of mild forms of the disease.

Author Contributions: F.C.-M., D.G.F.-P., and J.L.A. designed the experiments, which were later executed by J.S.V.-B. and J.L.A. The analysis of the obtained data was performed by F.C.-M., D.G.F.-P., F.J.F.C., and J.M.B. Lastly, all authors contributed to the writing of the manuscript.

Funding: This publication has been carried out in the framework of the Thematic Network for Co-Operative Research in Health (RETICS) reference number RD16/0008/0012 financed by the Carlos III Health Institute-General Subdirection of Networks and Cooperative Investigation Centers (R\&D\&I National Plan 2013-2016) and the European Regional Development Fund (FEDER).

Conflicts of Interest: The authors declare no conflict of interest.

\section{References}

1. DelMonte, D.W.; Kim, T. Anatomy and physiology of the cornea. J. Cataract Refract. Surg. 2011, 37, 588-598. [CrossRef] [PubMed]

2. Tong, J.; Bhimji, S.S. Anatomy, Head, Face, Eye, Muscles, Orbicularis Oculi; StatPearls Publishing LLC.: Treasure Island, FL, USA, 2018.

3. Maharana, P.K.; Dubey, A.; Jhanji, V.; Sharma, N.; Das, S.; Vajpayee, R.B. Management of advanced corneal ectasias. Br. J. Ophthalmol. 2016, 100, 34-40. [CrossRef] [PubMed]

4. Li, X.; Yang, H.; Rabinowitz, Y.S. Keratoconus: Classification scheme based on videokeratography and clinical signs. J. Cataract Refract. Surg. 2009, 35, 1597-1603. [CrossRef] [PubMed]

5. Roberts, C.J.; Dupps, W.J., Jr. Biomechanics of corneal ectasia and biomechanical treatments. J. Cataract. Refract. Surg. 2014, 40, 991-998. [CrossRef] [PubMed] 
6. Duncan, J.K.; Belin, M.W.; Borgstrom, M. Assessing progression of keratoconus: Novel tomographic determinants. Eye Vis. 2016, 3, 6. [CrossRef] [PubMed]

7. Rabinowitz, Y.S. Keratoconus. Surv. Ophthalmol. 1998, 42, 297-319. [CrossRef]

8. Alió, J.L.; Vega-Estrada, A.; Sanz-Díez, P.; Peña-García, P.; Durán-García, M.L.; Maldonado, M. Keratoconus management guidelines. Int. J. Keratoconus Ectatic Corneal Dis. 2015, 4, 1-39. [CrossRef]

9. Pinero, D.P.; Nieto, J.C.; Lopez-Miguel, A. Characterization of corneal structure in keratoconus. J. Cataract Refract. Surg. 2012, 38, 2167-2183. [CrossRef] [PubMed]

10. Arbelaez, M.C.; Versaci, F.; Vestri, G.; Barboni, P.; Savini, G. Use of a support vector machine for keratoconus and subclinical keratoconus detection by topographic and tomographic data. Ophthalmology 2012, 119, 2231-2238. [CrossRef] [PubMed]

11. Alio, J.L.; Pinero, D.P.; Aleson, A.; Teus, M.A.; Barraquer, R.I.; Murta, J.; Maldonado, M.J.; Castro de Luna, G.; Gutierrez, R.; Villa, C.; et al. Keratoconus-integrated characterization considering anterior corneal aberrations, internal astigmatism, and corneal biomechanics. J. Cataract Refract. Surg. 2011, 37, 552-568. [CrossRef] [PubMed]

12. Cavas-Martinez, F.; Fernandez-Pacheco, D.G.; De la Cruz-Sanchez, E.; Nieto Martinez, J.; Fernandez Canavate, F.J.; Vega-Estrada, A.; Plaza-Puche, A.B.; Alio, J.L. Geometrical custom modeling of human cornea in vivo and its use for the diagnosis of corneal ectasia. PLoS ONE 2014, 9, e110249. [CrossRef] [PubMed]

13. Ramos-Lopez, D.; Martinez-Finkelshtein, A.; Castro-Luna, G.M.; Pinero, D.; Alio, J.L. Placido-based indices of corneal irregularity. Optom. Vis. Sci. 2011, 88, 1220-1231. [CrossRef] [PubMed]

14. Piegl, L.; Tiller, W. The Nurbs Book; Government Printing Office: New York, NY, USA, 1997.

15. Cazon-Martin, A.; Matey-Muñoz, L.; Rodriguez-Ferradas, M.; Morer-Camo, P.; Gonzalez-Zuazo, I. Direct digital manufacturing for sports and medical sciences: Three practical cases. Dyna 2015, 90, 621-627.

16. Chakroun, F.; Colombo, V.; Lie Sam Foek, D.; Gallo, L.M.; Feilzer, A.; Ozcan, M. Displacement of teeth without and with bonded fixed orthodontic retainers: $3 \mathrm{~d}$ analysis using triangular target frames and optoelectronic motion tracking device. J. Mech. Behav. Biomed. Mater. 2018, 85, 175-180. [CrossRef] [PubMed]

17. Minatel, L.; Verri, F.R.; Kudo, G.A.H.; de Faria Almeida, D.A.; de Souza Batista, V.E.; Lemos, C.A.A.; Pellizzer, E.P.; Santiago, J.F.J. Effect of different types of prosthetic platforms on stress-distribution in dental implant-supported prostheses. Mater. Sci. Eng. C Mater. Biol. Appl. 2017, 71, 35-42. [CrossRef] [PubMed]

18. Xu, F.; Morganti, S.; Zakerzadeh, R.; Kamensky, D.; Auricchio, F.; Reali, A.; Hughes, T.J.R.; Sacks, M.S.; $\mathrm{Hsu}$, M.C. A framework for designing patient-specific bioprosthetic heart valves using immersogeometric fluid-structure interaction analysis. Int. J. Numer. Methods Biomed. Eng. 2018, 34, e2938. [CrossRef] [PubMed]

19. Robins, M.; Solomon, J.; Samei, E. Can a 3d task transfer function accurately represent the signal transfer properties of low-contrast lesions in non-linear CT systems? In Medical Imaging 2018: Physics of Medical Imaging; SPIE: Houston, TX, USA, 2018; p. 9.

20. Lanchares, E.; Del Buey, M.A.; Cristobal, J.A.; Calvo, B.; Ascaso, F.J.; Malve, M. Computational simulation of scleral buckling surgery for rhegmatogenous retinal detachment: On the effect of the band size on the myopization. J. Ophthalmol. 2016, 2016, 3578617. [CrossRef] [PubMed]

21. Cavas-Martínez, F.; Bataille, L.; Fernández-Pacheco, D.G.; Cañavate, F.J.F.; Alio, J.L. Keratoconus detection based on a new corneal volumetric analysis. Sci. Rep. 2017, 7, 15837. [CrossRef] [PubMed]

22. Giovanzana, S.; Kasprzak, H.T.; Pałucki, B.; Ţălu, Ş. Non-rotational aspherical models of the human optical system. J. Mod. Opt. 2013, 60, 1898-1904. [CrossRef]

23. Xie, W. Recent advances in laser in situ keratomileusis-associated dry eye. Clin. Exp. Optom. 2016, 99, 107-112. [CrossRef] [PubMed]

24. Anderson, K.; El-Sheikh, A.; Newson, T. Application of structural analysis to the mechanical behaviour of the cornea. J. R. Soc. Interface 2004, 1, 3-15. [CrossRef] [PubMed]

25. Gefen, A.; Shalom, R.; Elad, D.; Mandel, Y. Biomechanical analysis of the keratoconic cornea. J. Mech. Behav. Biomed. Mater. 2009, 2, 224-236. [CrossRef] [PubMed]

26. Cavas-Martínez, F.; Bataille, L.; Fernández-Pacheco, D.G.; Cañavate, F.J.F.; Alió, J.L. A new approach to keratoconus detection based on corneal morphogeometric analysis. PLoS ONE 2017, 12, e0184569. [CrossRef] [PubMed] 
27. Carvalho, L.A.; Prado, M.; Cunha, R.H.; Costa Neto, A.; Paranhos, A., Jr.; Schor, P.; Chamon, W. Keratoconus prediction using a finite element model of the cornea with local biomechanical properties. Arq. Bras. Oftalmol. 2009, 72, 139-145. [CrossRef] [PubMed]

28. Pandolfi, A.; Manganiello, F. A model for the human cornea: Constitutive formulation and numerical analysis. Biomech. Model. Mechanobiol. 2006, 5, 237-246. [CrossRef] [PubMed]

29. Sinha Roy, A.; Dupps, W.J., Jr. Patient-specific computational modeling of keratoconus progression and differential responses to collagen cross-linking. Investig. Opthalmol. Vis. Sci. 2011, 52, 9174-9187. [CrossRef] [PubMed]

30. Klyce, S.D.; Karon, M.D.; Smolek, M.K. Advantages and disadvantages of the zernike expansion for representing wave aberration of the normal and aberrated eye. J. Refract. Surg. 2004, 20, S537-S541. [PubMed]

31. Smolek, M.K.; Klyce, S.D. Goodness-of-prediction of zernike polynomial fitting to corneal surfaces. J. Cataract Refract. Surg. 2005, 31, 2350-2355. [CrossRef] [PubMed]

32. Iskander, D.R.; Collins, M.J.; Davis, B. Optimal modeling of corneal surfaces with zernike polynomials. IEEE Trans. Biomed. Eng. 2001, 48, 87-95. [CrossRef] [PubMed]

33. Kamiya, K.; Shimizu, K.; Igarashi, A.; Miyake, T. Assessment of anterior, posterior, and total central corneal astigmatism in eyes with keratoconus. Am. J. Ophthalmol. 2015, 160, 851-857. [CrossRef] [PubMed]

34. Belin, M.W.; Kim, J.T.; Zloty, P.; Ambrosio, R.J. Simplified nomenclature for describing keratoconu. Int. J. Keratoconus Ectatic Corneal Dis. 2012, 1, 31-35. [CrossRef]

35. Hernandez-Camarena, J.C.; Chirinos-Saldana, P.; Navas, A.; Ramirez-Miranda, A.; de la Mota, A.; Jimenez-Corona, A.; Graue-Hernindez, E.O. Repeatability, reproducibility, and agreement between three different scheimpflug systems in measuring corneal and anterior segment biometry. J. Refract. Surg. 2014, 30, 616-621. [CrossRef] [PubMed]

36. Tomidokoro, A.; Oshika, T.; Amano, S.; Higaki, S.; Maeda, N.; Miyata, K. Changes in anterior and posterior corneal curvatures in keratoconus. Ophthalmology 2000, 107, 1328-1332. [CrossRef]

37. Bayraktar Bilen, N.; Hepsen, I.F.; Arce, C.G. Correlation between visual function and refractive, topographic, pachymetric and aberrometric data in eyes with keratoconus. Int. J. Ophthalmol. 2016, 9, 1127-1133. [PubMed]

38. Montalban, R.; Alio, J.L.; Javaloy, J.; Pinero, D.P. Correlation of anterior and posterior corneal shape in keratoconus. Cornea 2013, 32, 916-921. [CrossRef] [PubMed]

39. Lopes, B.T.; Ramos, I.C.; Faria-Correia, F.; Luz, A.; de Freitas Valbon, B.; Belin, M.W.; Ambrósio, R.J. Correlation of topometric and tomographic indices with visual acuity in patients with keratoconus. Int. J. Keratoconus Ectatic Corneal Dis. 2012, 1, 167-172. [CrossRef]

40. Piñero, D.P.; Alió, J.L.; Aleson, A.; Escaf Vergara, M.; Miranda, M. Corneal volume, pachymetry, and correlation of anterior and posterior corneal shape in subclinical and different stages of clinical keratoconus. J. Cataract Refract. Surg. 2010, 36, 814-825. [CrossRef] [PubMed]

41. Prakash, G.; Suhail, M.; Srivastava, D. Predictive analysis between topographic, pachymetric and wavefront parameters in keratoconus, suspects and normal eyes: Creating unified equations to evaluate keratoconus. Curr. Eye Res. 2016, 41, 334-342. [CrossRef] [PubMed]

42. Mannion, L.S.; Tromans, C.; O'Donnell, C. Reduction in corneal volume with severity of keratoconus. Curr. Eye Res. 2011, 36, 522-527. [CrossRef] [PubMed]

(C) 2018 by the authors. Licensee MDPI, Basel, Switzerland. This article is an open access article distributed under the terms and conditions of the Creative Commons Attribution (CC BY) license (http://creativecommons.org/licenses/by/4.0/). 